\title{
Influence of plant and bacterial myrosinase activity on the metabolic fate of glucosinolates in gnotobiotic rats
}

\author{
Gabrielle Rouzaud ${ }^{1}$, Sylvie Rabot ${ }^{2}$, Brian Ratcliffe ${ }^{3}$ and Alan J. Duncan ${ }^{1 *}$ \\ ${ }^{1}$ Macaulay Institute, Craigiebuckler, Aberdeen AB15 8QH, UK \\ ${ }^{2}$ INRA, Unité d'Ecologie et de Physiologie du Système Digestif, Centre de Recherche de Jouy en Josas, \\ 78352 Jouy en Josas, France \\ ${ }^{3}$ Robert Gordon University, Queen's Road, Aberdeen AB15 4PH, UK
}

(Received 13 September 2002 - Revised 17 February 2003 - Accepted 22 March 2003)

\begin{abstract}
The breakdown of glucosinolates, a group of thioglucoside compounds found in cruciferous plants, is catalysed by dietary or microbial myrosinase. This hydrolysis releases a range of breakdown products among which are the isothiocyanates, which have been implicated in the cancer-protective effects of cruciferous vegetables. The respective involvement of plant myrosinase and gut bacterial myrosinase in the conversion, in vivo, of glucosinolates into isothiocyanates was investigated in sixteen Fischer 344 rats. Glucosinolate hydrolysis in gnotobiotic rats harbouring a whole human faecal flora (Flora+) was compared with that in germ-free rats (Flora-). Rats were offered a diet where plant myrosinase was either active (Myro+) or inactive (Myro-). The conversion of prop-2-enyl glucosinolate and benzyl glucosinolate to their related isothiocyanates, allyl isothiocyanate and benzyl isothiocyanate, was estimated using urinary mercapturic acids, which are endproducts of isothiocyanate metabolism. The highest excretion of urinary mercapturic acids was found when only plant myrosinase was active (Flora-, Myro+ treatment). Lower excretion was observed when both plant and microbial myrosinases were active (Flora+, Myro+ treatment). Excretion of urinary mercapturic acids when only microbial myrosinase was active (Flora+, Myro - treatment) was low and comparable with the levels in the absence of myrosinase (Flora-, Myro- treatment). No intact glucosinolates were detected in the faeces of rats from the Flora+ treatments confirming the strong capacity of the microflora to break down glucosinolates. The results confirm that plant myrosinase can catalyse substantial release of isothiocyanates in vivo. The results also suggest that the human microflora may, in some circumstances, reduce the proportion of isothiocyanates available for intestinal absorption.
\end{abstract}

Glucosinolates: Isothiocyanates: Excretion: Myrosinase: Human colonic microflora

The consumption of cruciferous vegetables, such as cabbage and Brussels sprouts, by human subjects has been shown in epidemiological studies to be associated with a reduced incidence of cancer, particularly of the digestive and respiratory tracts (Steinmetz \& Potter, 1991; Watson \& Kohlmeier, 1999). Cruciferous vegetables contain several antioxidants and phytochemicals, such as carotenoids, vitamin C, flavonoids and glucosinolates (GSL), which have been implicated in the protective effects of such vegetables against cancer (Beecher, 1994; Johnson et al. 1994). Whilst most of these phytochemicals are also found in a wide variety of non-cruciferous fruit and vegetables, the essential source of GSL in the human diet is limited to the cruciferous vegetables, a few condiments, such as mustard and horseradish, and one fruit, the papaya (Fenwick et al. 1983). The GSL have, therefore, aroused particular interest as potential mediators of the cancer-protective effects of brassica vegetables. It is, however, difficult to establish accurate estimates of target tissue exposure to GSL derivatives since information on the metabolic fate of GSL in vivo is limited.

The breakdown of GSL is thought to occur at two stages following their consumption by mammals. The first stage occurs when plant cells are disrupted during ingestion of plant material. This process exposes GSL to a plant enzyme, myrosinase (thioglucoside glucohydrolase, $E C$ 3.2.3.1) and hydrolysis occurs to yield several metabolites among which the isothiocyanates (ITC) have been implicated as cancer-protective compounds (Zhang \& Talalay, 1994; Hecht, 1999). This hydrolysis may occur in vivo under the action of plant myrosinase when vegetables are eaten raw. In this situation, the release of the ITC from the GSL precursor in vivo may primarily occur in the upper digestive tract. In these circumstances, it is hypothesized that ITC may be absorbed before reaching the colon, although no direct evidence for this phenomenon

\footnotetext{
Abbreviations: Flora+, presence of microflora; Flora-, absence of microflora; GSL, glucosinolate; ITC, isothiocyanate; Myro+, presence of dietary myrosinase activity; Myro-, absence of dietary myrosinase activity.

* Corresponding author: Dr Alan J. Duncan, fax +44 1224 311556, email a.duncan@macaulay.ac.uk
} 
is available. ITC taken up by the intestinal mucosa are subsequently metabolized by the liver before being released into the systemic circulation as their $\mathrm{N}$-acetyl cysteine conjugates and excreted in urine as their respective mercapturic acids (N-acetyl-S-(N-alkylthiocarbamoyl)-L-cysteines) (Conaway et al. 2002).

On the other hand, when vegetables are processed and cooked, plant myrosinase is inactivated (Ludikhuyze et al. 1999), which may limit the release of breakdown products. Intact GSL may reach the lower intestinal tract and be available as a substrate for the colonic microflora. The existence of microbial myrosinase activity in the microflora of the human bowel may catalyse the hydrolysis of GSL (Elfoul, 1999; Shapiro et al. 2001). The amount and site of release of GSL breakdown products probably, therefore, varies according to the activity of plant myrosinase, which will influence the amount of intact GSL reaching the large intestine. The different sites of hydrolysis following consumption of cooked and raw brassica vegetables may also influence the relative exposure of different tissues to ITC.

In the experiment reported here, the respective influence of dietary myrosinase and microbial myrosinase activity, and their interaction, on the release of ITC was measured in vivo in rats. The mode of administration of GSL, as a single dose or as part of a dietary regimen, may alter the fate of GSL; two modes of administration of GSL were therefore tested in the present experiment. The fate of dietary prop-2-enyl glucosinolate (sinigrin) contained in Brussels sprouts (Brassica oleracea var. gemmifera) and the fate of benzyl glucosinolate administered artificially were studied. The release of their related ITC was measured using mercapturic acids ( $\mathrm{N}$-acetyl $\mathrm{S}$-(N-alkylthiocarbamoyl)-L-cysteine) as markers of their appearance in vivo following GSL hydrolysis (Duncan et al. 1997).

\section{Material and methods}

\section{Experimental design}

The experiment was a $2 \times 2$ factorial design with factors consisting of presence or absence of dietary myrosinase activity (Myro+ and Myro- respectively) and presence or absence of microflora (Flora+ and Florarespectively). Two diets differing in myrosinase activity were offered to rats. One diet contained intact plant myrosinase (Myro+ diet) while the other diet contained the same cruciferous material heat-treated to inactivate the plant myrosinase (Myro- diet). To study the role of microbial myrosinase activity, two sets of animals differing in microbial status were used. The Flora + group consisted of eight rats harbouring a whole human faecal flora while the Flora - group consisted of eight germ-free rats. Study of the interaction between dietary and microbial myrosinase was achieved by offering the Myro+ or Myro - diets to rats from the Flora+ or Flora - groups. Within each group of rats differing in microflora status, the order of offering the two diets was balanced, with four animals receiving the Myro+ diet first followed by the Myro- diet and vice versa. The total duration of the experiment was $44 \mathrm{~d}$. Each period of feeding lasted $22 \mathrm{~d}$. In each feeding period, the first $8 \mathrm{~d}$ acted as an adaptation phase to allow rats to habituate to the food. The following $14 \mathrm{~d}$ were split into two dosing periods (see later; p. 397) lasting $7 \mathrm{~d}$ each.

\section{Animals}

Sixteen male, adult Fischer 344 rats were used. They were born germ-free and bred in germ-free conditions according to established methods (Coates, 1968) (INRA breeding unit, Jouy en Josas, France). Rats were aged 6-9 weeks at the start of the experiment (mean weight 163 (SD 11) g). Animals were randomly allocated to Flora+ and Floragroups. To maintain their bacterial status, rats were kept in groups of four animals in four sterile isolators (La Calhène, Vélizy, France). Within each isolator, rats were individually housed in metabolism cages (Iffa-Credo, Saint Germain sur l'Arbresle, France). Sterilized diet and autoclaved ultra-filtered water were given ad libitum to rats. On day 1, rats from the Flora+ group were orally administered with $1.0 \mathrm{ml} 10^{-2}$ dilution of a fresh faecal suspension. The faecal suspension was made from the stools of a healthy human male subject. Fresh stools $(2 \mathrm{~g})$ were dispersed in $20 \mathrm{ml}$ Difco Brain Heart Infusion medium (Becton Dickinson, Le Pont de Claix, France). The microbiological diversity of the inoculum was assessed by microscopic examination.

\section{Diet composition and preparation}

The Myro+ and Myro- diets were semi-synthetic diets simulating a human-type diet (Table 1). They contained $150 \mathrm{~g}$ freeze-dried Brussels sprouts (Brassica oleracea variety cyrus) $/ \mathrm{kg}$ DM (Novartis Seeds, Enkhuizen, The Netherlands). Analysis of GSL concentrations in the Brussels sprouts showed that sinigrin (prop-2-enyl glucosinolate) accounted for $54 \%$ of the total amount of identified GSL and that benzyl glucosinolate was absent (Table 2). Diets were pelleted and packed in doublevacuum bags, which were sterilized by $\gamma$ irradiation at 45 kGy (U.A.R, Villemoisson, France). In the Myro-diet, freeze-dried Brussels sprouts were treated to denature myrosinase before inclusion in the diet. Inactivation of myrosinase was achieved by soaking $100 \mathrm{~g}$ ground, freezedried Brussels sprouts in 1 litre $70 \%$ (v/v) boiling ethanol for $10 \mathrm{~min}$ at $75^{\circ} \mathrm{C}$. Ethanol was subsequently evaporated at $60^{\circ} \mathrm{C}$ using a rotary evaporator and aqueous residues were removed by oven-drying at $70^{\circ} \mathrm{C}$. The success of the inactivation process was verified by adding $0.2 \mathrm{~g}$ freezedried Brussels sprouts treated for myrosinase inactivation to $2 \mathrm{ml}$ distilled water. Duplicate samples were made and incubated at $37^{\circ} \mathrm{C}$ overnight. GSL concentrations were subsequently measured in the freeze-dried material and in the aqueous suspensions using the method of Minchinton et al. (1982). The inactivation process was considered successful if the difference between the concentration of sinigrin in the aqueous suspensions and in the freeze-dried Brussels sprouts was less than $10 \%$ (Table 2). 
Table 1. Composition of the diets ( $\mathrm{g} / \mathrm{kg}$ dry matter) given to germfree rats and rats harbouring a human faecal microflora

\begin{tabular}{lrr}
\hline & \multicolumn{2}{c}{ Diets } \\
\cline { 2 - 3 } Ingredients & Myro+ & Myro- \\
\hline Casein & $50 \cdot 00$ & 50.00 \\
Soya isolate & $90 \cdot 00$ & 90.00 \\
Brussels sprouts with native myrosinase & $150 \cdot 00$ & - \\
Brussels sprouts with denatured myrosinase & - & 150.00 \\
Saccharose & 50.00 & 50.00 \\
Mashed potato & 230.00 & 230.00 \\
Maize starch & 229.85 & 229.85 \\
Lard & 30.00 & 30.00 \\
Maize oil & 30.00 & 30.00 \\
Cholesterol & 0.15 & 0.15 \\
Cellulose & 60.00 & 60.00 \\
Mineral additiveł & 70.00 & 70.00 \\
Vitamin additive§ & 10.00 & 10.00 \\
Protein content & 15.70 & 16.07 \\
Energy (kJ/kg DM) & 16.83 & 17.08 \\
\hline
\end{tabular}

Myro+, diet with presence of myrosinase activity; Myro-, diet with absence of myrosinase activity.

* Soya protein isolate PP500E; Protein Technologies International (St Louis, MO, USA).

† Myrosinase was denatured by heat treatment

$¥$ The mineral additive included (g/kg DM of diet): $\mathrm{CaHPO}_{4} 30.1, \mathrm{KCl} 7.0$, $\mathrm{NaCl} 7.0, \mathrm{MgO}$ 0.735, $\mathrm{MgSO}_{4} 3.5, \mathrm{Fe}_{2} \mathrm{O}_{3}$ 0.21, $\mathrm{FeSO}_{4} .7 \mathrm{H}_{2} \mathrm{O} 0.35$ $\mathrm{MnSO}_{4} \cdot \mathrm{H}_{2} \mathrm{O} 0.17, \mathrm{CuSO}_{4} .5 \mathrm{H}_{2} \mathrm{O} 0.035, \mathrm{ZnSO}_{4} .7 \mathrm{H}_{2} \mathrm{O} 0.141, \mathrm{CoSO}_{4} .7 \mathrm{H}_{2} \mathrm{O}$ $2.8 \times 10^{-4}, \mathrm{KI} 5.6 \times 10^{-4}$

$\S$ The vitamin additive included ( $\mathrm{mg} / \mathrm{kg} \mathrm{DM}$ of diet): thiamin 20 , riboflavin 15 , pantothenic acid 70 , pyridoxine 10, myoinositol 150, cyanocobalamine 0.05 , ascorbic acid 800, $\alpha$-tocopherol 170 , menadione 40 , niacin 100 , choline 1360 , folic acid 5 , p-aminobenzoic acid 50 , biotin 0.3 , retinol 5.9 and cholecalciferol 0.0625 .

\section{Administration of glucosinolates and isothiocyanates}

The proportion of intact sinigrin and benzyl glucosinolate that were absorbed as allyl isothiocyanate and benzyl isothiocyanate from the gut was estimated in a similar fashion to a previous study (Duncan et al. 1997). Estimation of ITC release required the measurement of urinary output of mercapturic acids following two separate dosing events within each feeding period. On one occasion, urinary output of mercapturic acids arising from GSL precursors was measured (GSL dosing period). On another occasion urinary output of mercapturic acids derived directly from orally delivered ITC was quantified (ITC dosing period). Urinary mercapturic acid concentrations were then used to estimate ITC release as explained later (p. 398) and in Fig. 1. At the beginning of the GSL dosing period, a dose of benzyl glucosinolate was administered orally to rats. Sinigrin was ingested as part of the diet and its intake was measured by recording the daily food intake of individual rats over the GSL dosing period. At the beginning of the ITC dosing period, an oral dose of allyl and benzyl isothiocyanate was administered to rats. Butyl isothiocyanate was also given to all animals on both dosing occasions as a recovery standard. Doses were administered either on day 9 or 16 of each feeding period. The sequence of administration of the dosing mixtures was balanced within each sub-group of four rats. When the GSL dose was administered, animals received $25 \mu \mathrm{mol}$ benzyl glucosinolate (Merck, Darmstadt, Germany) diluted in $0.25 \mathrm{ml}$ water followed by $25 \mu \mathrm{mol}$ butyl isothiocyanate (Sigma, SaintQuentin Fallavier, France) diluted in $0.25 \mathrm{ml}$ maize oil. The ITC dose contained $25 \mu \mathrm{mol}$ each of allyl, benzyl and butyl isothiocyanates (Sigma) diluted in $0.25 \mathrm{ml}$ maize oil. The ITC dose was preceded by the administration of $0.25 \mathrm{ml}$ water so that all rats received equivalent amounts of the dosing vehicles. On each occasion, the doses were flushed with $0.25 \mathrm{ml}$ pure maize oil. The GSL dosing mixtures were sterilized by filtration $(0.22 \mu \mathrm{m}$ Millex-GS filters; Millipore, Saint Quentin-en-Yvelines, France) and the ITC mixtures by autoclaving, before being administered. Preliminary tests showed that sterilization procedures did not influence concentrations of GSL or ITC. Dosing mixtures were orally administered using a sterile stainless-steel stomach tube to rats under light diethyl ether anaesthesia.

\section{Sample collection}

The day before each dosing, metabolism cages were cleaned. Urine and faeces were subsequently collected at $0,6,24,48,72,120$ and $144 \mathrm{~h}$ after administration of dosing mixtures. To avoid bacterial degradation of urinary markers, sodium azide (final concentration $0.02 \%(\mathrm{v} / \mathrm{v})$; Sigma) was added to the urine collection receptacles of

Table 2. Concentrations of glucosinolates in the Brussels sprouts (Brassica oleracea variety cyrus) and in the diets given to rats $\left(\mu \mathrm{mol} / \mathrm{g}\right.$ dry matter) ${ }^{*}$

(Mean values and standard deviations)

\begin{tabular}{|c|c|c|c|c|c|c|}
\hline \multirow[b]{2}{*}{ Glucosinolates } & \multicolumn{2}{|c|}{ Brussels sprouts } & \multicolumn{2}{|c|}{$\begin{array}{l}\text { Myrosinase- } \\
\text { inactivated } \\
\text { Brussels sprouts }\end{array}$} & \multirow[b]{2}{*}{ Myro+ diet } & \multirow[b]{2}{*}{ Myro- diet } \\
\hline & Mean & SD & Mean & SD & & \\
\hline Glucoiberin & $3 \cdot 31$ & 0.08 & $4 \cdot 64$ & 0.42 & 0.50 & 0.70 \\
\hline Progoitrin & 2.96 & $0 \cdot 18$ & $3 \cdot 71$ & 0.35 & 0.44 & 0.56 \\
\hline Sinigrin & $12 \cdot 2$ & 0.04 & $11 \cdot 7$ & 0.76 & 1.83 & 1.76 \\
\hline Gluconapin & $2 \cdot 46$ & $0 \cdot 15$ & $2 \cdot 19$ & 0.19 & 0.37 & 0.33 \\
\hline 4-OH glucobrassicin & 2.91 & $0 \cdot 15$ & ND & ND & 0.43 & ND \\
\hline Glucobrassicin & 0.32 & 0.04 & 0.92 & 0.25 & 0.05 & 0.14 \\
\hline 4-Methoxy glucobrassicin & 0.58 & 0.08 & ND & ND & 0.09 & ND \\
\hline Total & $24 \cdot 74$ & 0.72 & $23 \cdot 24$ & 1.53 & 3.71 & 3.49 \\
\hline
\end{tabular}

Myro+, presence of myrosinase activity; Myro-, absence of myrosinase activity; ND, not detected.

${ }^{*}$ For details of diets and procedures, see Table 1 and p. 396. 


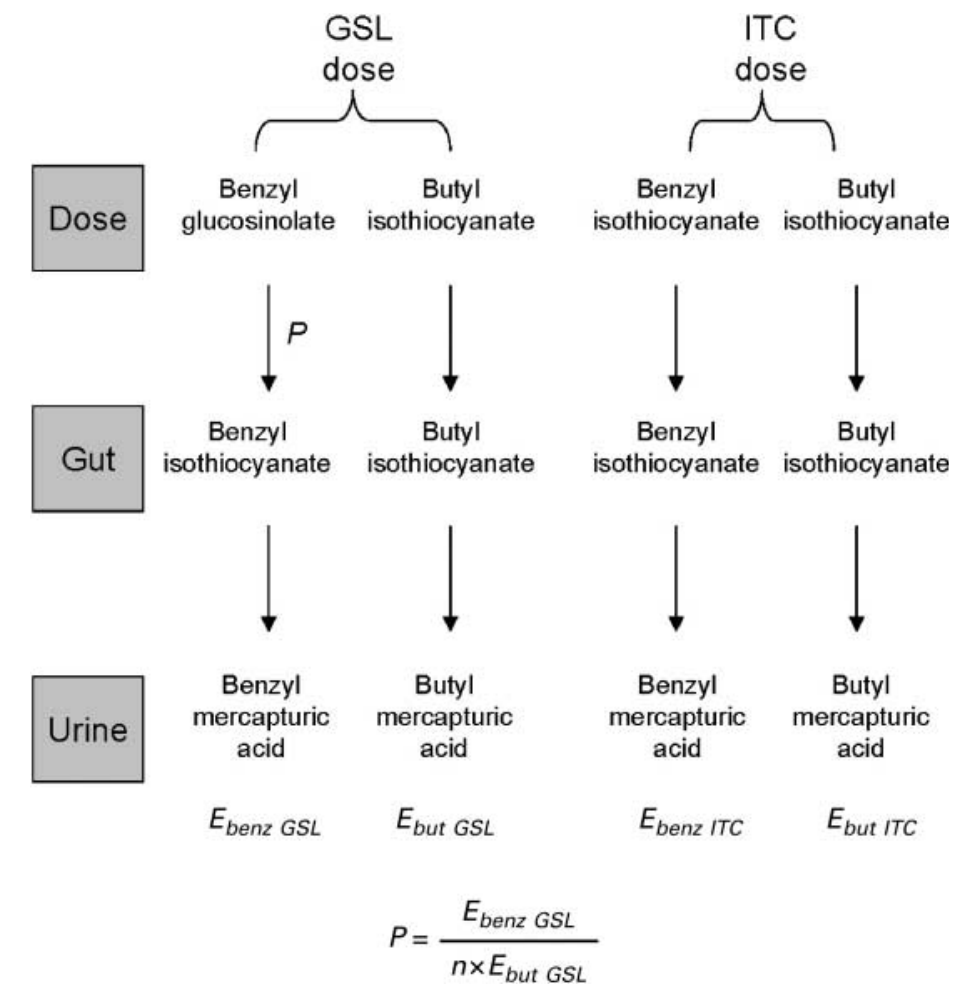

Fig. 1. Calculation of proportional release of benzyl isothiocyanate from benzyl glucosinolate following administration of benzyl glucosinolate to rats. GSL, glucosinolate; ITC, isothiocyanate; $P$, proportion of administered benzyl glucosinolate yielding benzyl isothiocyanate; benz, benzyl; but, butyl; $E$, molar amount of mercapturic acid excreted in $144 \mathrm{~h} ; n$, mean $\mathrm{E}_{\text {benzlTc }}: \mathrm{E}_{\text {butITc }}$ value in all rats.

the Flora+ group of rats. No sodium azide was added to the receptacles of the Flora- group since these animals were in a sterile environment. Preliminary tests showed that sodium azide did not interfere with the analysis.

\section{Analysis}

Analysis of urinary endproducts. Mercapturic acids in urine were analysed using a modification of the method of Mennicke et al. (1987). The isocratic HPLC analysis was replaced in the present study by a gradient of distilled water and acetonitrile to allow the separation of mercapturic acids of allyl, propyl, butyl and benzyl isothiocyanates. The mobile phase consisted of $30 \%(\mathrm{v} / \mathrm{v})$ acetonitrile in water changing linearly to $70 \%$ over $20 \mathrm{~min}$. Detection was by u.v. absorbance at $240 \mathrm{~nm}$. A solution of $1.5 \mathrm{~mm}-$ propyl mercapturic acid ( $N$-acetyl- $S$ - $(N$-propylthiocarbomoyl)-L-cysteine) was synthesized (Mennicke et al. 1983) and used as an internal standard. Preliminary analysis showed that $95 \%$ of mercapturic acids was excreted in $48 \mathrm{~h}$. Consequently, urine samples collected at times 72 , 120 and $144 \mathrm{~h}$ were bulked in proportion to their volume before analysis.

Analysis of intact glucosinolates in faeces. Residual GSL, recovered intact in the faeces, were measured after desulfatation. Before analysis, faeces samples were freeze-dried and ground. Phenethyl glucosinolate $(200 \mu \mathrm{l}$, $1.0 \mathrm{~mm}$; Sigma, Poole, Dorset, UK) was added to $0.2 \mathrm{~g}$ ground faeces as an internal standard. Samples were analysed in duplicate. Extraction of GSL was carried out twice using $15 \mathrm{ml}$ aliquots of $70 \%(\mathrm{v} / \mathrm{v})$ boiling methanol. Pooled extracts were concentrated by rotary evaporation to obtain a final volume of $5 \mathrm{ml}$ extract. Extracts were subsequently enzymically desulfated (Minchinton et al. 1982). Separation of desulfo-glucosinolates was carried out by HPLC (Gilson, Villiers le Bel, France) using a C18 reverse-phase column (Lichrospher $250 \times 4 \mathrm{~mm}$; Merck). The mobile phase consisted of pure distilled water changing to $20 \%(\mathrm{v} / \mathrm{v})$ acetonitrile in distilled water over $45 \mathrm{~min}$ as previously described (Spinks et al. 1984). Eluted peaks were detected by u.v. absorbance at $228 \mathrm{~nm}$ (u.v./visible detector, model 118; Gilson). Equimolar amounts of $1.0 \mathrm{~mm}$-sinigrin, benzyl glucosinolate and phenethyl glucosinolate, which had been desulfated identically to test samples, were used to determine the detector response factors of measured desulfo-glucosinolates relative to the internal standard.

\section{Calculations and statistical analysis}

Calculation of isothiocyanate release from precursor glucosinolates in the intestinal tract of rats. The molar amount of benzyl mercapturic acid recovered in the urine during the GSL dosing period was divided by the predicted amount of benzyl mercapturic acid that would have been excreted assuming complete hydrolysis of benzyl glucosinolate to benzyl isothiocyanate. This prediction was based on the mean benzyl:butyl mercapturic acids value in the urine of individual rats collected during the ITC 
dosing period multiplied by the amount of butyl mercapturic acid excreted during the GSL dosing period for each rat. Fig. 1 describes the calculation more fully. The calculation of allyl isothiocyanate released from sinigrin was based on the same principle.

Calculation of glucosinolate intake for individual rats and glucosinolate excretion in faeces. Daily food intake was averaged over the last $16 \mathrm{~d}$ of each feeding period. The amount of intact GSL excreted in the faeces of rats was calculated by multiplying faecal GSL concentrations by total faecal output.

Statistics. The experiment was analysed as a split-plot design using ANOVA. Isolator, isolator $\times$ rat, feeding period $\times$ isolator and feeding period $\times$ rat were treated as blocks in the analysis. Terms analysed as treatments in the ANOVA model were diet, microbial status, diet $\times$ microbial status, feeding period and dosing day. The effect of microbial status was analysed in the isolator stratum. The effect of diet and the interaction of diet with microbial status was analysed in the isolator $\times$ period stratum. All calculations were performed using Genstat 5 (Lawes Agricultural Trust, Harpenden, Herts, UK, 1995).

\section{Results}

\section{Intake and faecal recovery of glucosinolates}

Mean daily intake by individual rats was 17 (SEM 0.3) g DM. Rats harbouring an active microflora (Flora +$)$ ate significantly less than germ-free rats (Flora -$)(P<0.05$; Table 3), but the amount of sinigrin ingested by rats was not significantly affected by their bacterial status (Table 3). The amount of the Myro+ diet ingested by rats was marginally, but significantly, higher than the amount of Myro - diet ingested $(P<0.01$; Table 3$)$ and this variation was also observed in the intake of sinigrin. Rats ingested marginally more sinigrin when they were fed the Myro+ diet than when the Myro - diet was offered $(P<0.01$; Table 3$)$. In rats harbouring a microflora (Flora+), intact sinigrin and benzyl glucosinolate were not detected in faeces indicating total hydrolysis or absorption. Among germ-free rats (Flora-), a proportion of dosed benzyl glucosinolate and dietary sinigrin was recovered in the faeces and these amounts were higher when dietary myrosinase was inactive (Myro-) (Table 3 ).

\section{Excretion of mercapturic acids}

ITC were recovered as anticipated as mercapturic acids in the urine following their administration during the ITC period. Benzyl isothiocyanate was recovered more fully than butyl isothiocyanate following an equimolar dose (Table 4; mean proportional recoveries of 0.60 (SEM 0.041) and 0.41 (SEM 0.018) respectively). Microbial status and diet had no significant influence on urinary output of mercapturic acids following oral administration of butyl isothiocyanate and benzyl isothiocyanate (Table 4). Urinary excretion of benzyl and butyl isothiocyanates as their respective urinary mercapturic acids was correlated across animals (Fig. 2) confirming that concurrently administered butyl isothiocyanate could be used to reliably predict the post-absorptive recovery of benzyl isothiocyanate as its mercapturic acid when the GSL precursor was administered to animals in the GSL dosing period. Proportional recovery of the mercapturic acid derived

Table 3. Mean intake of experimental diets $(\mathrm{g} / \mathrm{d})$ and sinigrin $(\mu \mathrm{mol} / \mathrm{d})$ and faecal output of glucosinolates ( $\mu \mathrm{mol}$ per $144 \mathrm{~h})$ by rats during the glucosinolate dosing period*

(Mean values and standard errors of differences of means)

\begin{tabular}{|c|c|c|c|c|c|c|}
\hline \multirow[b]{2}{*}{ Precursor } & \multirow[b]{2}{*}{ Diet } & \multicolumn{2}{|c|}{ Bacterial status } & \multirow[b]{2}{*}{ Mean } & \multirow[b]{2}{*}{ SED } & \multirow[b]{2}{*}{ Level of significance (Myro $+v$. Myro-) } \\
\hline & & Flora+ & Flora- & & & \\
\hline Intake of pelleted food & $\begin{array}{l}\text { Myro+ } \\
\text { Myro- } \\
\text { Mean }\end{array}$ & $\begin{array}{l}16 \cdot 9 \\
15 \cdot 5 \\
16 \cdot 2\end{array}$ & $\begin{array}{l}18 \cdot 9 \\
16 \cdot 4 \\
17 \cdot 7\end{array}$ & $\begin{array}{l}17 \cdot 9 \\
16 \cdot 0\end{array}$ & 0.52 & $P<0.01$ \\
\hline Level of significance (Flora) & SED & \multicolumn{2}{|c|}{$\begin{array}{c}0.50 \\
P<0.05\end{array}$} & & & \\
\hline Intake of sinigrin & $\begin{array}{l}\text { Myro+ } \\
\text { Myro- } \\
\text { Mean }\end{array}$ & $\begin{array}{l}30 \cdot 9 \\
27 \cdot 3 \\
29 \cdot 1\end{array}$ & $\begin{array}{l}34.6 \\
28.9 \\
31.7\end{array}$ & $\begin{array}{l}32 \cdot 7 \\
28 \cdot 1\end{array}$ & 1.50 & $P<0.01$ \\
\hline Level of significance (Flora) & SED & \multicolumn{2}{|c|}{$\begin{array}{l}1.80 \\
\text { NS }\end{array}$} & & & \\
\hline $\begin{array}{l}\text { Faecal output of benzyl } \\
\text { glucosinolate }(\mu \mathrm{mol} \text { over } 144 \mathrm{~h}) \dagger\end{array}$ & $\begin{array}{l}\text { Myro+ } \\
\text { Myro- } \\
\text { Mean }\end{array}$ & $\begin{array}{l}<0.001 \\
<0.001 \\
<0.001\end{array}$ & $\begin{array}{l}2.0 \\
8.5 \\
5.3\end{array}$ & $\begin{array}{l}1 \cdot 0 \\
4 \cdot 3\end{array}$ & $1 \cdot 85$ & $P<0.01$ \\
\hline Level of significance (Flora) & SED & \multicolumn{2}{|c|}{$\begin{array}{c}1.81 \\
P<0.01\end{array}$} & & & \\
\hline $\begin{array}{l}\text { Faecal output of dietary sinigrin } \\
(\mu \mathrm{mol} \text { over } 144 \mathrm{~h}) \dagger\end{array}$ & $\begin{array}{l}\text { Myro+ } \\
\text { Myro- } \\
\text { Mean }\end{array}$ & $\begin{array}{l}<0.001 \\
<0.001 \\
<0.001\end{array}$ & $\begin{array}{l}0.05 \\
27 \cdot 1 \\
12.7\end{array}$ & $\begin{array}{l}0.028 \\
12 \cdot 7\end{array}$ & $5 \cdot 26$ & $P<0.01$ \\
\hline Level of significance (Flora) & SED & \multicolumn{2}{|c|}{$\begin{array}{c}4.15 \\
P<0.01\end{array}$} & & & \\
\hline
\end{tabular}

Flora+, rats harbouring a human faecal microflora; Flora-, germ-free rats; Myro+, presence of myrosinase activity; Myro-, absence of myrosinase activity; NS, not significant at $P<0.05$.

* For details of diets and procedures, see Tables 1 and 2 and p. 396

$\dagger$ Amount of mercapturic acids below the threshold of HPLC detection $(0.001 \mu \mathrm{mol})$ were considered as $0.001 \mu \mathrm{mol}$ in the statistical analysis. 
Table 4. Cumulative excretion of urinary mercapturic acids ( $\mu \mathrm{mol}$ ) over $144 \mathrm{~h}$ after administration of an isomolar solution of allyl, benzyl and butyl isothiocyanates to rats differing in microbial status and diet offered*

(Mean values and standard errors of differences of means)

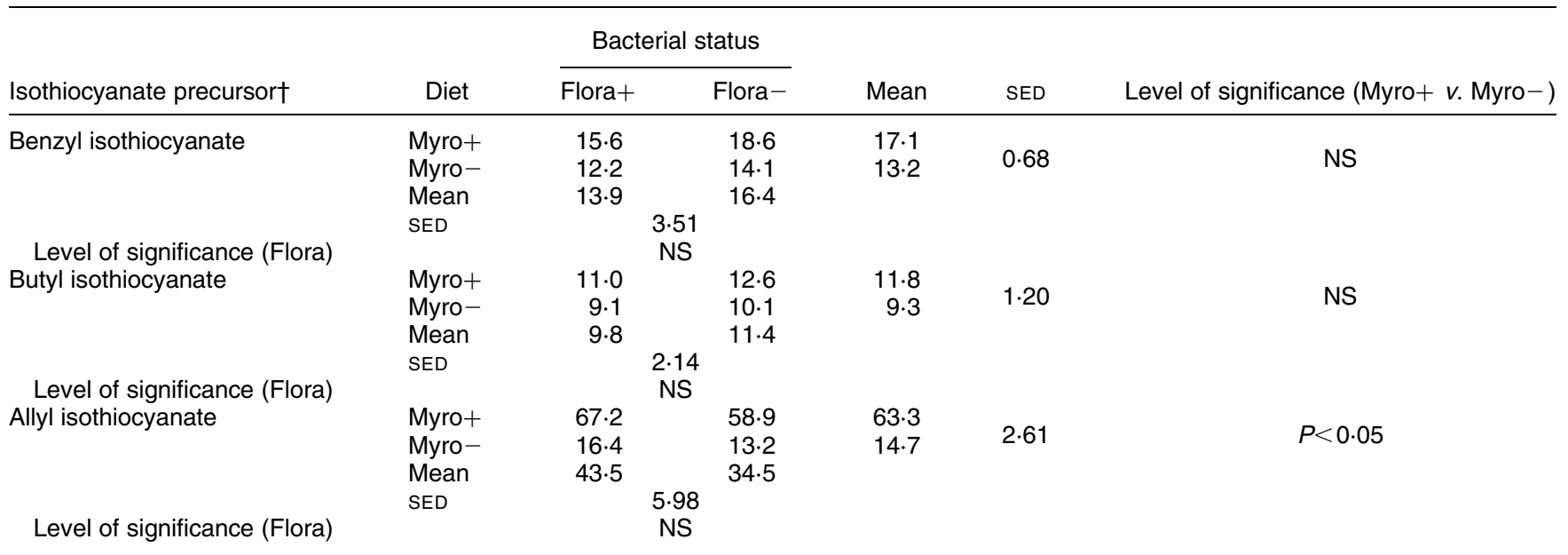

Flora+, rats harbouring a human faecal microflora; Flora-, germ-free rats; Myro+, presence of myrosinase activity; Myro-, absence of myrosinase activity; NS, not significant at $P<0.05$.

${ }^{*}$ For details of diets and procedures, see Tables 1 and 2 and p. 000.

† Isothiocyanate solution contained $25 \mu \mathrm{mol}$ of allyl, butyl and benzyl isothiocyanate.

from allyl isothiocyanate following the ITC dose was greater than 1.0 due to the presence of sinigrin in the diet, which led to production of allyl isothiocyanate of dietary origin in the gut. Excretion of the mercapturic acid from allyl isothiocyanate was significantly higher when rats were fed the Myro+ diet $v$. the Myro- diet but excretion was not significantly different in the presence or absence of microbial activity (Table 4).

Mercapturic acids were also detected in the urine collected during the GSL dosing period. Mean proportional recovery of benzyl glucosinolate as benzyl mercapturic acid was 0.16 (SEM 0.032). Diet had a significant influence on the excretion of benzyl mercapturic acid following the GSL dose. Excretion was higher when rats were consuming the Myro+ diet than when the Myro- diet was offered

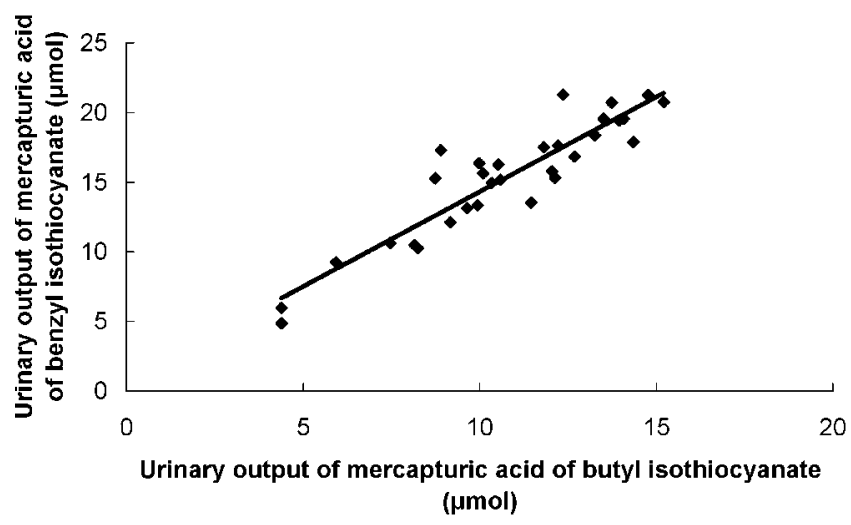

Fig. 2. Relationship between cumulative excretion of mercapturic acids of butyl and benzyl isothiocyanate after administration of isothiocyanate dose: $y=(1.36 \times x)+0.67 \quad\left(R^{2}=0.847 ; \quad P<0.001\right)$ where $y$ is the urinary output of mercapturic acid of benzyl isothiocyanate over $144 \mathrm{~h}$ and $x$ is the urinary output of mercapturic acid of butyl isothiocyanate over $144 \mathrm{~h}$.
(Table 5) indicating GSL hydrolysis by intact myrosinase present in the Myro+ diet. The urinary output of benzyl mercapturic acid was higher in the Flora- rats than in the Flora+ rats indicating a negative effect of the presence of the microflora on the amount of benzyl isothiocyanate available for intestinal uptake. The highest excretion of benzyl mercapturic acid was found when plant myrosinase only was active (Flora-, Myro+) (Table 5). When both sources of myrosinase were active (Flora+, Myro+), the urinary output of benzyl mercapturic acid was lower than when plant myrosinase only was active. In the absence of myrosinase (Flora-, Myro-) excretion of benzyl mercapturic acid was close to zero. Benzyl mercapturic acid excretion when bacterial myrosinase only was active (Flora+, Myro-) was also close to zero. The sequence of offering the diet had no significant effect on excretion of benzyl mercapturic acid. Excretion of butyl mercapturic acid during the GSL dosing period followed a similar pattern to its excretion during the ITC dosing period. Neither diet nor microbial status significantly influenced urinary output of dosed butyl isothiocyanate as its mercapturic acid and mean proportional recovery was 0.38 (SEM 0.032). Excretion of allyl mercapturic acid during the GSL dosing period was strongly influenced by diet with higher excretion in rats consuming the Myro+ diet than those consuming the Myro- diet (Table 5). Microbial status had no significant influence on allyl mercapturic acid excretion.

\section{Estimation of proportional release of benzyl isothiocyanate}

The estimated proportional release of benzyl isothiocyanate from benzyl glucosinolate in the digestive tract was considerably higher in rats consuming a diet containing intact myrosinase than in rats consuming a myrosinase-free diet $(P<0.05 ;$ Table 6). In rats harbouring a microflora, 
Table 5. Cumulative excretion of urinary mercapturic acids ( $\mu \mathrm{mol}$ ) excreted over $144 \mathrm{~h}$ after simultaneous administration of $25 \mu \mathrm{mol}$ benzyl glucosinolate and butyl isothiocyanate to rats differing in microbial status and diet offered ${ }^{\star}$

(Mean values and standard errors of differences of means)

\begin{tabular}{|c|c|c|c|c|c|c|}
\hline \multirow[b]{2}{*}{ Precursor } & \multirow[b]{2}{*}{ Diet } & \multicolumn{2}{|c|}{ Bacterial status } & \multirow[b]{2}{*}{ Mean } & \multirow[b]{2}{*}{ SED } & \multirow[b]{2}{*}{ Level of significance (Myro $+v$. Myro-) } \\
\hline & & Flora+ & Flora- & & & \\
\hline Benzyl glucosinolate & $\begin{array}{l}\text { Myro+ } \\
\text { Myro- } \\
\text { Mean }\end{array}$ & $\begin{array}{l}5.1 \\
0.42 \\
2.75\end{array}$ & $\begin{array}{l}9.8 \\
0.40 \\
5.14\end{array}$ & $\begin{array}{l}7.5 \\
0.41\end{array}$ & 0.54 & $P<0.05$ \\
\hline Level of significance (Flora) & SED & \multicolumn{2}{|c|}{$\begin{array}{l}0.30 \\
P<0.05\end{array}$} & & & \\
\hline Butyl isothiocyanate & $\begin{array}{l}\text { Myro+ } \\
\text { Myro- } \\
\text { Mean } \\
\text { SED }\end{array}$ & $\begin{array}{r}8.6 \\
10.0 \\
9.3\end{array}$ & $\begin{array}{r}10.7 \\
9.2 \\
10.0\end{array}$ & $\begin{array}{l}9.6 \\
9.6\end{array}$ & 1.02 & NS \\
\hline Level of significance (Flora) & & & & & & \\
\hline Level of significance (Flora) & $\begin{array}{l}\text { Myro+ } \\
\text { Myro- } \\
\text { Mean } \\
\text { SED }\end{array}$ & $\begin{array}{r}31.8 \\
4.7 \\
18.3\end{array}$ & $\begin{array}{c}42.4 \\
0.84 \\
21.6\end{array}$ & $\begin{array}{r}37 \cdot 1 \\
2 \cdot 8\end{array}$ & $1 \cdot 83$ & $P<0.05$ \\
\hline
\end{tabular}

Flora+, rats harbouring a human faecal microflora; Flora-, germ-free rats; Myro+, presence of myrosinase activity; Myro-, absence of myrosinase activity; NS, not significant at $P<0.05$.

*For details of diets and procedures, see Tables 1 and 2 and p. 396.

proportional release of benzyl isothiocyanate was lower than in germ-free rats $(P<0 \cdot 05)$. The interaction between microbial status and diet was not significant.

\section{Discussion}

A fuller understanding of the cancer-protective effects of GSL requires more information about the fate of GSL from their synthesis in plant cells to their absorption from the gut as breakdown products and delivery to tissues. Recent studies on the effect of cooking on brassica vegetables have provided a better appreciation of the fate of GSL during food preparation (Dekker et al. 2000). The fate of GSL following ingestion is much less well understood. Recent experiments, demonstrating the release of ITC in the lower gut following microbial hydrolysis (Elfoul et al. 2001; Shapiro et al. 2001), have aroused interest since ITC may exhibit their cancer-protective effect on the colorectal epithelium (Smith et al. 1998) and ingestion of brassica vegetables is particularly associated with inhibition of tumour occurrence at this site.
In the present experiment, urinary mercapturic acids were used as markers of ITC release. Such an approach has been successfully used in other studies (Duncan et al. 1997; Shapiro et al. 1998; Getahun \& Chung, 1999) to estimate ITC production in the digestive tract under different circumstances. Before their excretion in urine as mercapturic acids, ITC undergo a series of biotransformation reactions involving conjugation with glutathione under the catalysis of glutathione-S-transferase (Mennicke et al. 1983). The efficiency of the conjugation step as well as the availability of conjugation substrates may vary between individuals and may limit the reliability of mercapturic acids used as markers of metabolism. Recovery of artificially administered ITC as urinary mercapturic acids did show considerable inter-individual variation in the present experiment (Fig. 2). The administration of butyl isothiocyanate, a compound that did not occur in the diet but which follows a similar detoxification pathway to foodborne ITC, allowed variation in the post-absorptive fate of ITC to be accounted for. The use of butyl isothiocyanate as a recovery standard relies on it having a similar metabolic fate to ITC formed following GSL hydrolysis.

Table 6. Estimated proportion of benzyl isothiocyanate released in the digestive tract of germ-free rats (Flora-) and rats harbouring a whole human faecal flora (Flora + ) following administration of $25 \mu \mathrm{mol}$ benzyl glucosinolate*

(Mean values and standard errors of differences of means)

\begin{tabular}{|c|c|c|c|c|c|c|}
\hline \multirow[b]{2}{*}{ Precursor } & \multirow[b]{2}{*}{ Diet } & \multicolumn{2}{|c|}{ Bacterial status } & \multirow[b]{2}{*}{ Mean } & \multirow[b]{2}{*}{ SED } & \multirow[b]{2}{*}{ Level of significance (Myro+ $v$. Myro-) } \\
\hline & & Flora+ & Flora- & & & \\
\hline Benzyl glucosinolate & $\begin{array}{l}\text { Myro+ } \\
\text { Myro- } \\
\text { Mean }\end{array}$ & $\begin{array}{l}0.50 \\
0.05 \\
0.27\end{array}$ & $\begin{array}{l}0.80 \\
0.04 \\
0.42\end{array}$ & $\begin{array}{l}0.65 \\
0.05\end{array}$ & 0.049 & $P<0.05$ \\
\hline Level of significance (Flora) & SED & \multicolumn{2}{|c|}{$\begin{array}{c}0.029 \\
P<0.05\end{array}$} & & & \\
\hline
\end{tabular}

Myro+, presence of myrosinase activity; Myro-, absence of myrosinase activity.

${ }^{\star}$ For details of diets and procedures, see Tables 1 and 2, p. 396. 
This assumption may not be fully satisfied since its instantaneous introduction into the digestive tract may influence its recovery relative to the more gradual appearance of GSL-derived ITC. Furthermore, recovery following oral administration into the upper digestive tract may be different from recovery following production in the lower digestive tract under microbial action. The use of a recovery standard does, however, represent an improvement on previous studies in which inter-individual variation in postabsorptive recovery has not been accounted for. Although absolute values for ITC production may not be precise, the use of a recovery standard increases the confidence of estimates of the release of ITC in the digestive tract.

The present study was designed to allow the relative influence of dietary and microbial myrosinase, as well as their interaction, on GSL hydrolysis to be assessed. Diets differed in their activity of plant myrosinase and contained similar concentrations of GSL, ensuring that the observed difference in breakdown product release was not related to a modification of the GSL composition of the diets. The method of treating Brussels sprouts to simulate cooking (by soaking in boiling ethanol) was effective in denaturing myrosinase but may also have had unknown effects on various other characteristics of the vegetable. Cooking of brassica vegetables leads to myrosinase inactivation and this probably is the major effect of cooking on GSL metabolism. GSL hydrolysis is, however, a complex process and it is conceivable that other changes to the vegetable may also have influenced the course of GSL hydrolysis. Little is known of the influence of changes in brassica vegetables following cooking, other than changes to myrosinase activity, on GSL hydrolysis and further research in this area would be useful.

The substantial release of allyl and benzyl isothiocyanate when rats were fed the Myro+ diet, which simulated the intake of raw cruciferous vegetables, confirmed that conditions in the digestive tract are favourable to ITC production from GSL after disruption of plant cells. This supports the findings of previous studies where human subjects have been fed raw cruciferous vegetables and mercapturic acids have been detected in the urine indicating ITC release (Shapiro et al. 1998; Getahun \& Chung, 1999). Previous estimates of ITC release have, however, been limited by uncertainty about the post-absorptive recovery of ITC.

In the present study, the proportional release of benzyl isothiocyanate by microbial myrosinase, as estimated by the excretion of its mercapturic acid, was relatively low (0.05; Table 6). This conflicts with previous studies, which have indicated more substantial release of ITC under the action of myrosinase of bacterial origin (Duncan et al. 1997; Elfoul et al. 2001). There are various possible explanations for this finding: GSL hydrolysis by microbial myrosinase may have led to non-ITC metabolites being produced; benzyl isothiocyanate may have been produced but its post-absorptive recovery may have been less efficient than when it arose in the upper tract; finally, benzyl isothiocyanate may have arisen in the colon but been further metabolized by micro-organisms before its absorption and excretion as its mercapturic acid. Contrary to expectations, the effect of plant myrosinase was not enhanced by the myrosinase activity of the microflora.
Indeed, the presence of an active microflora reduced the excretion of the mercapturic acid arising from benzyl isothiocyanate. These observations suggest that the microflora may be able to catalyse both the release of ITC and their further breakdown to other final products resulting in a lower net absorption of ITC by the distal digestive tract in the presence of an active microflora. A recent study, identifying the production of allyl amine and benzyl amine as a result of the microbial hydrolysis of sinigrin and benzyl glucosinolate by human microflora (Combourieu et al. 2001), would appear to support these observations.

When both sources of myrosinase were active, the proportion of benzyl glucosinolate broken down to benzyl isothiocyanate found in the present studies (0.50) was similar to previous findings on allyl isothiocyanate release from sinigrin in conventional rats (0.41; Duncan et al. 1995). The amounts were also broadly similar to previous estimates derived from feeding trials where human volunteers ingested raw cruciferous vegetables (Shapiro et al. 1998, 2001).

The proportion of allyl isothiocyanate released from dietary sinigrin could not be confidently estimated in the present study. Due to the background excretion of allyl mercapturic acid, the correlation between the excretion of butyl isothiocyanate and allyl isothiocyanate administered in the ITC dose was poor. Butyl isothiocyanate could not, therefore, be used as a predictor of allyl isothiocyanate recovery since allyl mercapturic acid in urine originated both from dietary sinigrin and dosed allyl isothiocyanate. While precise estimates of allyl isothiocyanate release were not possible, the amounts of allyl mercapturic acid excreted in urine and intact sinigrin excreted in faeces under the various treatments applied were in broad agreement with information derived from benzyl glucosinolate.

Information about the fate of GSL in the digestive tract can also be derived from the extent of their recovery in faeces. When plant myrosinase only was active, the total amount of dosed benzyl glucosinolate accounted for by ITC release and faecal excretion on a molar basis was 0.84 of the amount dosed. This high proportion suggests that other breakdown products of myrosinase hydrolysis, such as nitriles, were only released in minor amounts when GSL were ingested in their intact form. Isothiocyanates therefore appeared to be the major products of GSL hydrolysis in the digestive tract.

The presence of the intestinal microflora presumably led to a total degradation or absorption of GSL since intact GSL were not detected in the faeces of the Flora+ rats. This finding supports the suggestion that the human microflora is able to effectively degrade GSL. Several studies have shown similar effects in vitro following incubation of human faeces and using human single strains of bacteria (Rabot et al. 1995; Getahun \& Chung, 1999; Krul et al. 2002).

Faecal recovery of GSL was not complete when both dietary and microbial myrosinase were inactive. Only 0.34 of dosed benzyl glucosinolate was excreted in the faeces of Flora+ rats consuming a Myro- diet. In a parallel experiment the faecal recovery of sinigrin was similar at 0.28 (Elfoul, 1999). These results suggest a possible 
metabolism other than enzymic hydrolysis for the proportion of GSL $(66-72 \%)$ that are not accounted for. It has been shown in vitro, using everted intestinal sacs, that GSL may passively cross the intestinal mucosa (Michaelsen et al. 1994). No evidence exists, however, for this mechanism occurring in vivo. The measurement of intact GSL in tissues and fluids other than faeces would be necessary to clarify the fate of non-digested GSL.

The microflora of rats in the Flora+ treatment were derived from a single healthy human subject. Multiple donors were not used since in previous work it has been found that such an approach leads to unpredictable interactions that result in a reduction of the degradative potential (Krul et al. 2002). The composition of the microflora was not determined due to the limitations of conventional culture techniques and since molecular techniques require cDNA probes that are only currently available for a few taxa. Bacterial myrosinase is, anyway, thought to be ubiquitous in man and this idea is supported by findings where the excretion of urinary endproducts dramatically decreased after consumption of GSL when a number of human volunteers were subjected to bowel cleansing and antibiotherapy (Shapiro et al. 1998). Although large differences in the composition and xenobiotic metabolizing capacity between human and rat intestinal microflora are well documented (Debure et al. 1989; Rumney et al. 1993; Meselhy et al. 1997), various studies have demonstrated that enzyme activities of the human colonic flora, for example, hydrolysis of glucuronides and hydroxylation of heterocyclic compounds, can be reliably simulated in human-flora-associated rats (Mallett et al. 1987; Debure et al. 1989; Rumney et al. 1993). Therefore, despite uncertainties surrounding the taxonomic and metabolic profiles of the flora of humanflora-associated rats, these animals are probably a more suitable model than conventional rats to investigate xenobiotic metabolism in the human context.

Under the conditions tested in the present experiment, plant myrosinase had a dominant influence on the production of ITC with microbial myrosinase having less marked effects. Myrosinase contained in a diet simulating raw vegetable consumption induced a substantial and rapid release of ITC. In contrast, after ingestion of a diet simulating cooked vegetables, the ITC were released to a lesser extent, if at all. This finding contrasts with previous studies in which the microflora appeared to catalyse ITC release (Elfoul et al. 2001, Shapiro et al. 2001). In the present study the microflora may have contributed to the release of ITC in vivo with a proportion of these newly formed ITC being further metabolized before they could be absorbed from the digestive tract. Alternatively, the microflora may have caused degradation of GSL and metabolism to other breakdown products. Absorption of ITC following consumption of brassica vegetables probably reflects the relative rates of production and further degradation of ITC. Further work is required before drawing general conclusions on the influence of the microflora on GSL hydrolysis. The present experiment has demonstrated the importance of the treatment of brassica material before ingestion (for example, cooking) in influencing the extent and site of production of ITC from GSL ingested as part of the diet. Further work is required to correlate the extent and site of ITC release from brassica vegetables prepared in different manners with protection against tumour formation at different tissue sites.

\section{Acknowledgements}

The authors would like to thank Mrs Solène Garrido and Mrs Sheila Young for technical assistance and Mr José Durao for the care of the animals. Professor John Milne and Professor Iain Gordon of the Macaulay Institute made helpful comments on the draft manuscript. This research was supported by the European Community under the programme FAIR CT97 3029 entitled 'Effects of food-borne glucosinolates on human health'.

\section{References}

Beecher CWW (1994) Cancer preventive properties of varieties of Brassica oleracea: a review. Am J Clin Nutr 59, Suppl., $1166 \mathrm{~S}-1170 \mathrm{~S}$.

Coates ME (1968) The Germ-free Animal in Research. London: Academic Press.

Combourieu B, Elfoul L, Delort AM \& Rabot S (2001) Identification of new derivatives of sinigrin and glucotropaeolin produced by the human digestive microflora using (1)H NMR spectroscopy analysis of in vitro incubations. Drug Metab Dispos 29, 1440-1445.

Conaway CC, Yang YM \& Chung FL (2002) Isothiocyanates as cancer chemopreventive agents: Their biological activities and metabolism in rodents and humans. Curr Drug Metab 3, $233-255$.

Debure A, Colombel JF, Flourie B, Rautureau M \& Rambaud JC (1989) Comparaison de l'implantation et de l'activité métabolique d'une flore fécale de rat et d'une flore fécale humaine, inoculée chez le rat axénique (Comparison of the composition and metabolic activities of a rat and a human faecal flora inoculated into germ-free rats). Gastroenterol Clin Biol 13, 25-31.

Dekker M, Verkerk R \& Jongen WMF (2000) Predictive modelling of health aspects in the food production chain: a case study on glucosinolates in cabbage. Trends Food Sci Technol 11, 174-181.

Duncan AJ, Rabot S \& Nugon-Baudon L (1995) Urinary mercapturic acids as markers for the estimation of isothiocyanate release from parent glucosinolates in the digestive tract of rats. In Proceedings of the 9th International Rapeseed Congress, Rapeseed Today and Tomorrow, pp. 928-929 [D Murphy, editor]. Cambridge, UK: Royal Society of Chemistry.

Duncan AJ, Rabot S \& Nugon-Baudon L (1997) Urinary mercapturic acids as markers for the determination of isothiocyanate release from glucosinolates in rats fed a cauliflower diet. $J$ Sci Food Agric 73, 214-220.

Elfoul L (1999) Bioconversion de la Sinigrine, Microconstitutant des Légumes Crucifères, par une Souche Colique Humaine de Bacteroides Thetaiotaomicron (Bioconversion of Sinigrin, a Microconstituent of Brassica Vegetables, by a Human Colonic Strain of Bacteroides Thetaiotatomicron). PhD thesis. Orsay, France: Université de Paris-Sud.

Elfoul L, Rabot S, Khelifa N, Quinsac A, Duguay A \& Rimbault A (2001) Formation of allyl isothiocyanate from sinigrin in the digestive tract of rats monoassociated with a 
human colonic strain of Bacteroides thetaiotaomicron. FEMS Microbiol Lett 197, 99-103.

Fenwick GR, Heaney RK \& Mullin WJ (1983) Glucosinolates and their breakdown products in food and food plants. CRC Critical Rev Food Sci Nutr 18, 123-201.

Getahun SM \& Chung F-L (1999) Conversion of glucosinolates to isothiocyanates in humans after ingestion of cooked watercress. Cancer Epidemiol Biomarkers Prev 8, 447-451.

Hecht SS (1999) Chemoprevention of cancer by isothiocyanates, modifiers of carcinogen metabolism. J Nutr 129, 768S-774S.

Johnson IT, Williamson G \& Musk SRR (1994) Anticarcinogenic factors in plant foods: a new class of nutrients? Nutr Res Rev 7, $175-204$.

Krul C, Humblot C, Philippe C, et al. (2002) Metabolism of sinigrin (2-propenyl glucosinolate) by the human colonic microflora in a dynamic in vitro large intestinal model. Carcinogenesis 23, 1009-1016.

Ludikhuyze L, Ooms V, Weemaes C \& Hendrickx M (1999) Kinetic study of the irreversible thermal and pressure inactivation of myrosinase from broccoli (Brassica oleracea L-Cv. Italica). J Agric Food Chem 47, 1794-1800.

Mallett AK, Bearne CA, Rowland IR, Farthing MJG, Cole CB \& Fuller R (1987) The use of rats associated with a human fecal flora as a model for studying the effects of diet on the human gut microflora. J Appl Bacteriol 63, 39-45.

Mennicke WH, Görler K \& Krumbiegel G (1983) Metabolism of some naturally occurring isothiocyanates in the rat. Xenobiotica 13, 203-207.

Mennicke WH, Kral T, Krumbiegel G \& Rittmann N (1987) Determination of $\mathrm{N}$-acetyl-S-(N-alkylthiocarbamoyl)-L-cysteine, a principal metabolite of alkyl isothiocyanates, in rat urine. J Chromatogr 414, 19-24.

Meselhy MR, Nakamura N \& Hattori M (1997) Biotransformation of (-)epicatechin 3-O-gallate by human intestinal bacteria. Chem Pharm Bull 45, 888-893.

Michaelsen S, Otte J, Simonsen L-O \& Sørensen H (1994)
Absorption and degradation of individual intact glucosinolates in the digestive tract of rodents. Acta Agric Scand 44A 25-37.

Minchinton IR, Sang JP, Burke D \& Truscott RJW (1982) Separation of desulphoglucosinolates by reversed-phase high-performance liquid chromatography. J Chromatogr 247, 141-148.

Rabot S, Guerin C, Nugon-Baudon L \& Szylit O (1995) Glucosinolate degradation by bacterial strains isolated from a human intestinal microflora. In Proceedings of the 9th International Rapeseed Congress, Rapeseed Today and Tomorrow, pp. 212-214 [D Murphy, editor]. Cambridge, UK: Royal Society of Chemistry.

Rumney CJ, Rowland IR \& O'Neil IK (1993) Conversion of IQ to 7OHIQ by gut microflora. Nutr Cancer 27, 250-255.

Shapiro TA, Fahey JW, Wade KL, Stephenson KK \& Talalay P (1998) Human metabolism and excretion of cancer chemoprotective glucosinolates and isothiocyanates of cruciferous vegetables. Cancer Epidemiol Biomarkers Prev 7, 1091-1100.

Shapiro TA, Fahey JW, Wade KL, Stephenson KK \& Talalay P (2001) Chemoprotective glucosinolates and isothiocyanates of broccoli sprouts: metabolism and excretion in humans. Cancer Epidemiol Biomarkers Prev 10, 501-508.

Smith TK, Lund EK, Musk SRR \& Johnson IT (1998) Inhibition of DMH induced aberrant crypt foci and induction of apoptosis in rat colon, following oral administration of a naturally occurring glucosinolate. Carcinogenesis 19, 967-973.

Spinks EA, Sones K \& Fenwick GR (1984) The quantitative analysis of glucosinolates in cruciferous vegetables, oilseeds and forage crops using high performance liquid chromatography. Fette Seifen Anstr 6, 228-231.

Steinmetz KA \& Potter JD (1991) Vegetables, fruit, and cancer. I. Epidemiology. Cancer Causes Control 2, 325-357.

Watson SH \& Kohlmeier L (1999) Crucifera, glucosinolates and colon cancer. FASEB J 13, A919.

Zhang Y \& Talalay P (1994) Anticarcinogenic activities of organic isothiocyanates: chemistry and mechanisms. Cancer Res 54 Suppl., 1976s-1981s. 